\title{
SISTEM INFORMASI PERAWATAN TANAMAN BERBASIS INTERNET OF THINGS DI TAMAN BALAD CIPARAY KABUPATEN BANDUNG
}

\author{
Rosmalina, S. T., M. Kom. ${ }^{1}$, Yaya Suharya, S. Kom., M. T ${ }^{2}$, Megantari Suhendar ${ }^{3}$ \\ 1 Program Studi Sistem Informasi Universitas Bale Bandung \\ ${ }^{2}$ Program Studi Teknik Informatika Universitas Bale Bandung \\ ${ }^{3}$ Program Studi Sistem Informasi Universitas Bale Bandung \\ Email: ${ }^{1}$ rosmalina.ros@gmail.com, ${ }^{2}$ yaya@cdi.co.id, ${ }^{3}$ megantari.suhendar@gmail.com
}

\begin{abstract}
Balad is a place of business, which has a minimalist garden on the second floor. The provision of water or watering and lighting to plants is one of the important things to keep the plants alive. Information systems on plant care based on the Internet of Things help in collecting information related to conditions such as humidity, temperature, soil fertility, and plant inspection that can be controlled via a smartphone using the internet network. Internet of Things makes use of plant owners to connect with their residence or place of business from anywhere and anytime. The remote sensor structure using Microcontroller ESP8266 is used to monitor the condition of plants in the Balad park, of course, to see conditions remotely. Designing Plant Care Information Systems based on the Internet of Things, can reduce costs and update productivity standards in maintaining small-scale plants and if needed can be developed on a large scale
\end{abstract}

Keywords : Arduino, Information Systems, Plant Care, Internet of Things, ESP8266.

\begin{abstract}
ABSTRAK
Balad merupakan salah satu tempat usaha, yang memiliki taman minimalis pada lantai dua. Pemberian air atau penyiraman serta pencahayaan terhadap tanaman, merupakan salah satu hal yang penting untuk menjaga agar tanaman dapat hidup dengan baik. Sistem Informasi pada perawatan tanaman berbasis Internet of Things membantu dalam mengumpulkan informasi terkait keadaan seperti kelembapan, suhu, kesuburan tanah, dan pemeriksaan tanaman yang dapat dikontrol melalui smartphone menggunakan jaringan internet. Internet of Things memanfaatkan pemilik tanaman untuk terhubung dengan kediaman atau tempat usahanya dari mana saja dan kapan saja. Struktur sensor jarak jauh menggunakan Microcontroller ESP8266 digunakan untuk memantau kondisi tanaman di taman Balad, tentunya untuk melihat kondisi dari jarak jauh. Perancangan Sistem Informasi Perawatan Tanaman berbasis Internet of Things, dapat mengurangi biaya dan memperbarui standar produktivitas dalam memelihara tanaman baik skala kecil dan lebih luasnya bila dibutuhkan dapat dikembangkan dalam skala besar.
\end{abstract}

Kata Kunci: Arduino, Sistem Informasi, Perawatan Tanaman, Internet of Things, ESP8266

\section{PENDAHULUAN}

\subsection{Latar Belakang}

Balad merupakan salah satu tempat usaha, yang memiliki taman minimalis pada lantai dua. Keterbatasan lahan yang dimiliki oleh Balad, membuat pemilik usaha memanfaatkan kondisi lahan yang ada untuk memelihara tanaman dalam skala kecil. Taman tersebut biasanya ditanami beraneka ragam tanaman agar memperindah dan membuat taman di Balad menjadi sejuk. Pada masa kini setiap orang memiliki kesibukanya masingmasing, berlaku sama pula pada pemilik usaha di Balad, sehingga terkadang terlupakan untuk merawat tanaman karena keterbatasan waktu. Tanaman yang ditanam oleh pemilik usaha agar tumbuh dengan baik harus mendapatkan konsumsi air, pencahayaan yang cukup. Pemberian air atau penyiraman serta pencahayaan terhadap tanaman, merupakan salah satu hal yang penting untuk menjaga agar tanaman dapat hidup dengan baik. Melihat kondisi tersebut pemilik usaha harus melakukan penyiraman secara rutin agar tanaman tersebut mendapatkan konsumsi air yang cukup. Sistem Informasi pada perawatan tanaman berbasis Internet of Things membantu dalam mengumpulkan informasi terkait keadaan seperti kelembapan, suhu, kesuburan tanah, dan pemeriksaan tanaman yang dapat dikontrol melalui smartphone menggunakan aplikasi. Internet of Things memanfaatkan pemilik tanaman untuk terhubung dengan kediaman atau tempat usahanya dari mana saja dan kapan saja. Struktur sensor jarak jauh menggunakan Microcontroller ESP8266 untuk memantau kondisi tanaman di taman Balad, tentunya untuk melihat kondisi dari jarak jauh. Perancangan Sistem Informasi Perawatan Tanaman berbasis Internet of Things, dapat mengurangi biaya dan memperbarui standar produktivitas dalam memelihara tanaman 
baik skala kecil dan lebih luasnya bila dibutuhkan dapat dikembangkan dalam skala besar.

Berdasarkan latar belakang yang telah dijelaskan sebelumnya, maka rumusan masalah pada penelitian ini adalah bagaimana cara membuat Sistem Informasi Perawatan Tanaman Otomatis menggunakan Teknologi Internet of Things?

Batasan masalah dalam penelitian ini adalah :

1. Penulis akan membuat Sistem Informasi Perawatan Tanaman Otomatis menggunakan Teknologi berbasis Internet of Things (IoT)

2. Penulis akan membuat Aplikasi berupa Pengontrolan, Monitoring, dan Statistik terkait kondisi tanaman, yang dapat diakses secara langsung menggunakan jaringan internet pada smartphone.

Tujuan dalam penelitian ini adalah :

1. Menciptakan Sistem Informasi untuk menghindari kelalaian pengguna dalam merawat tanaman, tentunya dengan melakukan perawatan tanaman, baik itu penyiraman ataupun pencahayaan secara rutin dan otomatis

2. Menciptakan Sistem Informasi untuk membantu pekerjaan manusia dengan memantau kondisi suhu dan kelembapan tanaman kapanpun, dimanapun dengan mudah menggunakan jaringan internet pada perangkat smartphone.

Penelitian terdahulu yang digunakan dalam penelitian ini antara lain :

Tabel 1 Penelitian Terdahulu

\begin{tabular}{|c|c|c|c|}
\hline No & $\begin{array}{l}\text { Nama } \\
\text { Peneliti }\end{array}$ & $\begin{array}{l}\text { Judul } \\
\text { Penelitian }\end{array}$ & Hasil Penelitian \\
\hline 1 & $\begin{array}{l}\text { Affan Bachri } \\
\text {,Eko Wahyu } \\
\text { Santoso } \\
\text { (Bachri \& } \\
\text { Utomo, } \\
\text { 2017) }\end{array}$ & $\begin{array}{l}\text { Prototype } \\
\text { Penyiram } \\
\text { Tanaman } \\
\text { Otomatis } \\
\text { Dengan } \\
\text { Sensor } \\
\text { Kelembaban } \\
\text { Tanah } \\
\text { Berbasis } \\
\text { Atmega } 328\end{array}$ & $\begin{array}{l}\text { Prototype penyiram } \\
\text { tanaman otomatis } \\
\text { dirancang } \\
\text { menggunakan tiga } \\
\text { sensor sebagai input. } \\
\text { Mini system atmega } \\
\text { dijadikan sebagai } \\
\text { kontrol untuk } \\
\text { menampilkan LCD } \\
\text { dan Menjalankan } \\
\text { Water pump } \\
\text { sebagai Output. } \\
\text { Prototype berjalan saat } \\
\text { suhu atau } \\
\text { kelembaban berkurang } \\
\text { untuk menghidupkan } \\
\text { water } \\
\text { pump. Ultrasonik yang } \\
\text { bekerja berdasarkan } \\
\text { pantulan } \\
\text { sinar ultrasonik } \\
\text { membaca jarak } \\
\text { ketinggian air pada } \\
\text { penampung air }\end{array}$ \\
\hline 2 & $\begin{array}{l}\text { Tulus } \\
\text { Pranata, } \\
\text { Beni Irawan, } \\
\text { Ilhamsyah } \\
\text { (Tulus } \\
\text { Pranata, } \\
\text { Beni Irawan, } \\
\text { 2015) }\end{array}$ & $\begin{array}{l}\text { Penerapan } \\
\text { logika fuzzy } \\
\text { Pada sistem } \\
\text { penyiraman } \\
\text { tanaman } \\
\text { otomatis } \\
\text { Berbasis } \\
\text { mikrokontrole }\end{array}$ & $\begin{array}{l}\text { Sistem penyiraman } \\
\text { tanaman otomatis } \\
\text { yang } \\
\text { mengintegrasikan } \\
\text { konsep logika fuzzy } \\
\text { dengan } \\
\text { mikrokonteroler telah } \\
\text { berhasil dibuat. }\end{array}$ \\
\hline
\end{tabular}

\begin{tabular}{|c|c|c|c|}
\hline & & & $\begin{array}{l}\text { Hasilnya dapat dilihat } \\
\text { dari serangkaian } \\
\text { pengujian yang telah } \\
\text { dilakukan, dimana } \\
\text { mikrokontroler } \\
\text { mampu melakukan } \\
\text { proses-proses } \\
\text { perhitungan sesuai } \\
\text { dengan aturan-aturan } \\
\text { fuzzy yang telah } \\
\text { diprogram pada } \\
\text { mikrokontroler } \\
\end{array}$ \\
\hline 3 & $\begin{array}{l}\text { Nikesh } \\
\text { Gondchawar } \\
\text { 1, Prof. Dr. } \\
\text { R. S. } \\
\text { Kawitkar } \\
\text { (Sinhgad } \\
\text { college of } \\
\text { Engineering, } \\
\text { Pune, India) } \\
\text { (Gondchawa } \\
\text { r \& } \\
\text { Kawitkar, } \\
\text { 2016) }\end{array}$ & $\begin{array}{l}\text { IoT based } \\
\text { Smart } \\
\text { Agriculture }\end{array}$ & $\begin{array}{lr}\text { Penelitian } & \text { ini } \\
\text { bertujuan } & \text { untuk } \\
\text { membuat pertanian } \\
\text { cerdas menggunakan } \\
\text { otomatisasi } r \text { dan } \\
\text { teknologi IoT. Fitur } \\
\text { utama dari proyek ini } \\
\text { termasuk robot } \\
\text { kendali jarak jauh } \\
\text { berbasis GPS pintar } \\
\text { untuk melakukan } \\
\text { tugas-tugas seperti } \\
\text { penyiangan, } \\
\text { penyemprotan, } \\
\text { penginderaan } \\
\text { kelembaban, menakut- } \\
\text { nakuti burung dan } \\
\text { hewan, } \\
\text { kewaspadaan, dll. }\end{array}$ \\
\hline 4 & $\begin{array}{l}\text { Jonshon } \\
\text { Tarigan, } \\
\text { Minsyahril } \\
\text { Bukit } \\
\text { (Tarigan \& } \\
\text { Bukit, 2018) }\end{array}$ & $\begin{array}{l}\text { Rancang } \\
\text { bangun sistem } \\
\text { penyiraman } \\
\text { tanaman } \\
\text { secara mandiri } \\
\text { berbasis } \\
\text { mikrokontroll } \\
\text { er atmega } \\
8535 \quad\end{array}$ & $\begin{array}{l}\text { Penelitian ini } \\
\text { dilakukan dengan } \\
\text { merancang, membuat } \\
\text { dan } \\
\text { mengimplementasikan } \\
\text { komponen-komponen } \\
\text { sistem yang meliputi } \\
\text { mikrokontroller } \\
\text { sebagai pengendali, } \\
\text { driver relay untuk } \\
\text { memghiupkan dan } \\
\text { mematikan pompa } \\
\text { Air, dan LCD (linquit } \\
\text { Cristal Display) untuk } \\
\text { menampilkan nilai } \\
\text { kelembaban tanah. }\end{array}$ \\
\hline 5 & $\begin{array}{l}\text { Vishal } \\
\text { gotarene, } \\
\text { Sandeep } \\
\text { Raskar } \\
\text { (Gotarane \& } \\
\text { Raskar, } \\
\text { 2020) }\end{array}$ & $\begin{array}{l}\text { Smart } \\
\text { Irrigation } \\
\text { Environment }\end{array}$ & $\begin{array}{lr}\text { Lingkungan } & \text { irigasi } \\
\text { cerdas } & \text { telah } \\
\text { direncanakan } & \text { dan } \\
\text { dicoba secara } & \text { efektif. } \\
\text { Ini telah } & \text { dibuat } \\
\text { dengan } & \\
\text { menggabungkan } & \\
\text { semua } & \text { bagian } \\
\text { peralatan } & \text { yang } \\
\text { digunakan } & \\
\end{array}$ \\
\hline 6 & $\begin{array}{l}\text { Dr.N.Suma, } \\
\text { Sandra Rhea } \\
\text { Samson, } \\
\text { S.Saranya, } \\
\text { G.Shanmuga } \\
\text { priya, } \\
\text { R.Subhashri } \\
\text { (Suma et al., } \\
\text { 2017) } \\
\end{array}$ & $\begin{array}{l}\text { IOT Based } \\
\text { Smart } \\
\text { Agriculture } \\
\text { Monitoring } \\
\text { System }\end{array}$ & $\begin{array}{l}\text { Proyek ini mencakup } \\
\text { berbagai fitur seperti } \\
\text { pemantauan jarak jauh } \\
\text { berbasis GPS, } \\
\text { penginderaan } \\
\text { kelembaban dan suhu, } \\
\text { keamanan, } \\
\text { kelembaban daun dan } \\
\text { irigasi yang tepat }\end{array}$ \\
\hline 7 & $\begin{array}{l}\text { Jash Doshi, } \\
\text { Tirthkumar } \\
\text { Patel, } \\
\text { Santosh } \\
\text { kumar } \\
\text { Bharti }\end{array}$ & $\begin{array}{l}\text { Smart } \\
\text { Farming } \\
\text { Using IoT, a } \\
\text { Solution for } \\
\text { Optimally } \\
\text { Monitoring }\end{array}$ & $\begin{array}{lr}\text { IoT memanfaatkan } \\
\text { petani } \\
\text { menghubungkan } \\
\text { dengan r tempat } \\
\text { tinggalnya. Kamera } \\
\text { jarak jauh digunakan }\end{array}$ \\
\hline
\end{tabular}




\begin{tabular}{|l|l|l|l|}
\hline $\begin{array}{l}\text { (Doshi et al., } \\
\text { 2019) }\end{array}$ & $\begin{array}{l}\text { Farming } \\
\text { Conditions }\end{array}$ & $\begin{array}{l}\text { untuk melihat kondisi } \\
\text { jarak jauh sebagai } \\
\text { video dan gambar }\end{array}$ \\
\hline
\end{tabular}

\subsection{Tinjauan Pustaka}

1. Sistem Informasi

Sistem informasi mencakup sejumlah komponen (manusia, komputer, teknologi informasi, dan prosedur kerja ) ada sesuatu yang diproses (data menjadi informasi) dan dimaksudkan untuk mencapai suatu sasaran atau tujuan.(Kadir, 2014)

\section{Perawatan Tanaman}

Perawatan tanaman secara umum merupakan kegiatan-kegiatan yang berkaitan dengan menjaga kelangsungan hidup tanaman agar tanaman tumbuh secara optimal. Pemeliharaan tanaman sangatlah penting, karena merupakan salah satu faktor penentu dalam produktivitas tanaman. Semakin baik proses pemeliharaan tanaman maka tingkat produktivitas tanaman akan semakin tinggi. Sehingga dapat disimpulkan bahwa perawatan tanaman ini adalah tindakan manusia yang bertujuan untuk memberi kondisi lingkungan yang sesuai dengan syarat tumbuh tanaman sehingga tanaman dapat tumbuh optimal.

\section{Internet of Things}

Menurut Cirani, Simone (2019:80) Internet of Things atau dikenal juga dengan singkatan IoT, merupakan sebuah konsep yang bertujuan untuk meperluas manfaat dari konektivitas internet yang tersambung secara terus-menerus. Adapun kemampuan seperti berbagi data, remmote control dan sebagainya, termasuk juga pada benda di dunia nyata. Internet of Things ditandai dengan adopsi pendekatan yang sangat sederhana untuk perangkat interkoneksi dengan mengandalkan ketersediaan layanan cloud, yang perlu dilakukan oleh semua pembuat sistem adalah menghubungkan berbagai hal ke Internet (baik melalui jaringan seluler atau dalam format banyak kasus melalui gateway yang terhubung ke Internet) dan mengirim semua data uplink ke cloud. Layanan cloud kemudian akan menyediakan penyimpanan fasilitas untuk semua data yang dikirim oleh perangkat di satu sisi, dan berbasis HTTP antarmuka untuk akses oleh client

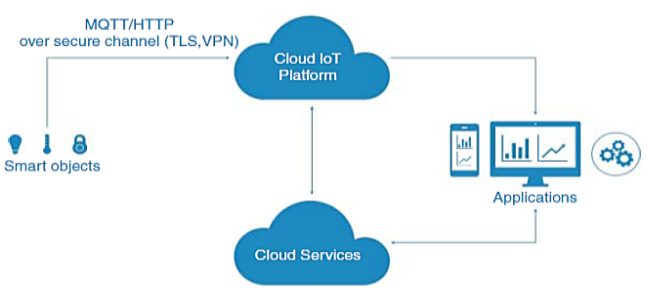

dapat dilihat pada gambar 1 dibawah ini.

Gambar 1 Cloud IoT Platform Architecture Komunikasi Hardware pada IoT dapat dilihat pada gambar 2 berikut.
- Communication Module: Ini memberi objek pintar komunikasinya kemampuan. Ini biasanya berupa transceiver radio dengan ekstensi antena atau koneksi kabel.

- Microcontroller: Ini memberi objek pintar perilakunya. Itu kecil mikroprosesor yang menjalankan perangkat lunak objek pintar.

- Sensors or Actuators: Ini memberi objek pintar cara untuk merasakan dan berinteraksi dengan dunia fisik.

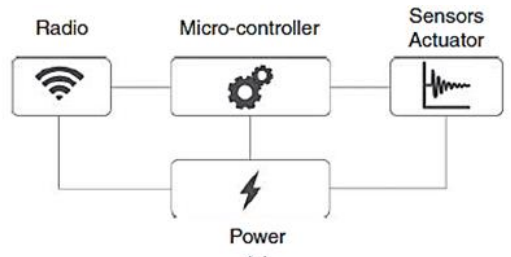

(a)

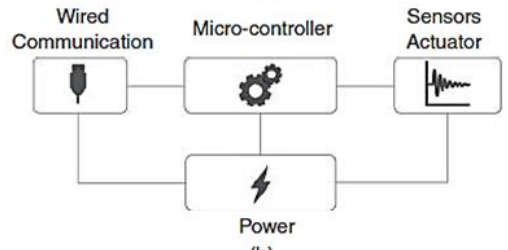

(b)

Gambar 2 Komunikasi pada IoT

\section{Modul WiFi ESP8266}

Menurut Santos (2017:10) Microcontroller ESP8266 adalah modul WiFi dengan prosesor ARM yang sangat bagus untuk memperluas fungsionalitas mikrokontroler seperti Arduino. Itu dapat berkomunikasi dengan mikrokontroler melalui serial. ESP8266 adalah SOC nirkabel integrasi tinggi, yang dirancang untuk perancang platform seluler dengan ruang dan daya yang tak terbatas.

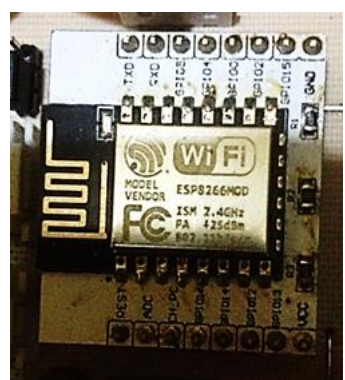

Gambar 3 Modul WiFi ESP8266

\section{Sensor DHT11}

Sensor DHT11 memiliki dua bagian sensor, yaitu sensor kelembapan kapasitif dan termistor. Pada sensor DHT11 juga terdapat sebuah chip yang melakukan konversi analog ke digital dan 
mengeluarkan sinyal digital terkait suhu dan kelembapan.(Istiyanto, 2018)

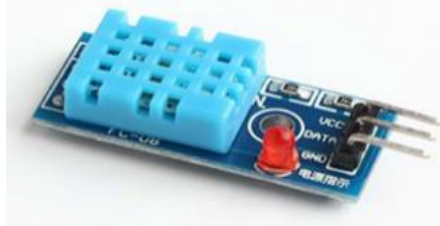

Gambar 4 Sensor DHT11

\section{Sensor DS18B20}

Sensor DS18B20 adalah sensor yang mampu membaca suhu dengan ketelitian 9 hingga 12-bit, rentang $-55^{\circ} \mathrm{C}$ hingga $125^{\circ} \mathrm{C}$ dengan ketelitian (+/$0.5^{\circ} \mathrm{C}$ ). Setiap sensor yang diproduksi memiliki kode unik sebesar 64-Bit yang disematkan pada masing-masing chip, sehingga memungkinkan penggunaan sensor dalam jumlah besar hanya melalui satu kabel saja (single wire data bus/1-wire protocol).

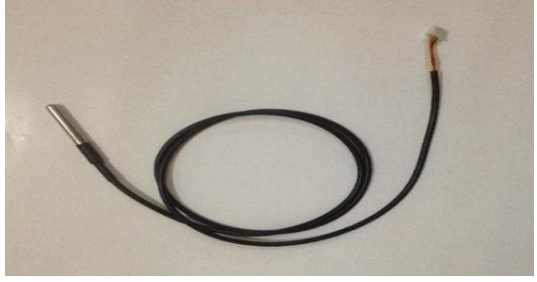

Gambar 5 Sensor DS18B20

\section{Sensor YL69}

Sensor YL 69 merupakan sensor yang mampu mendeteksi kelembapan dalam tanah. Sensor kelembapan tanah mengukur kadar air volumetrik dalam tanah..

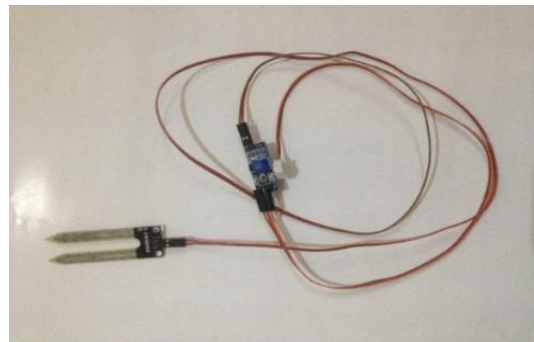

Gambar 6 Sensor YL69

\subsection{Metodologi}

Dalam penelitian disini metodologi yang digunakan metode SDLC (System Development Life Cycle) dengan model Waterfall, dimana apabila dituangkan kedalam kerangka pikir pada penelitian adalah sebagai berikut.

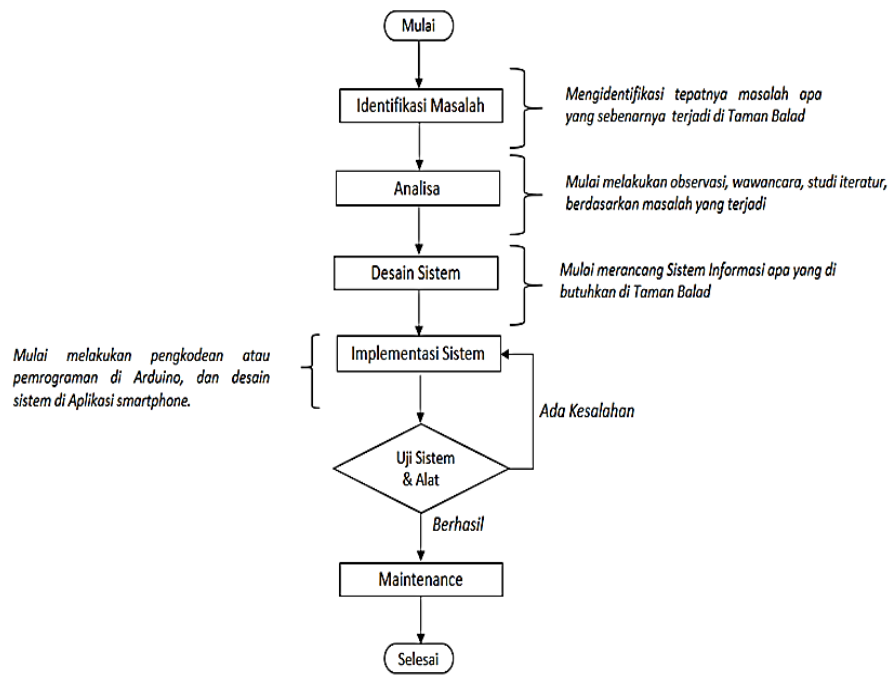

Gambar 7 Metodologi

\section{PEMBAHASAN}

\subsection{Analisis}

Pada gambar 8 dijelaskan mengenai analisis sistem yang berjalan

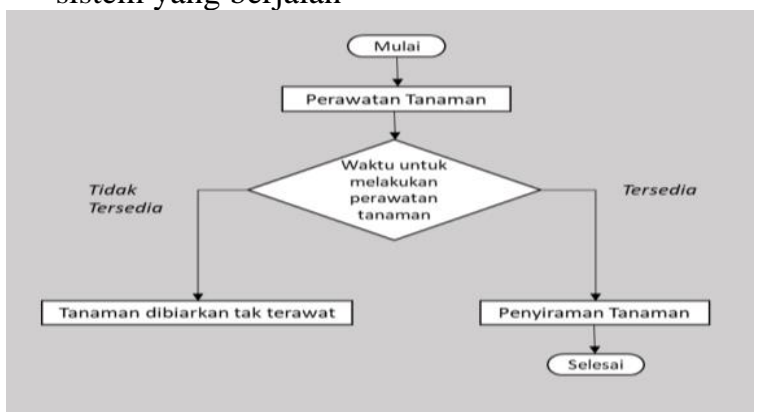

Gambar 8 Analisis Sistem yang Berjalan

Melihat sistem yang berjalan saat in di taman Balad, serta hasil survey para responden, dimana terkadang lupa atau tak memiliki waktu untuk merawat tanaman mereka dengan maksimal, karena berbagai macam kesibukan yang dimiliki. Sedangkan untuk sistem usulan, penulis akan membuat sistem baru yang dinamakan Sistem Informasi Perawatan Tanaman berbasis Internet of Things.

Dimana sistem ini memiliki kelebihan, yaitu mampu melakukan perawatan tanaman secara otomatis, baik itu penyiraman, ataupun pencahayaan melalui jaringan internet yang telah terintegrasi dengan hardware, sehingga kondisi tanaman dapat dimonitor secara langsung melalui aplikasi pada smartphone. 


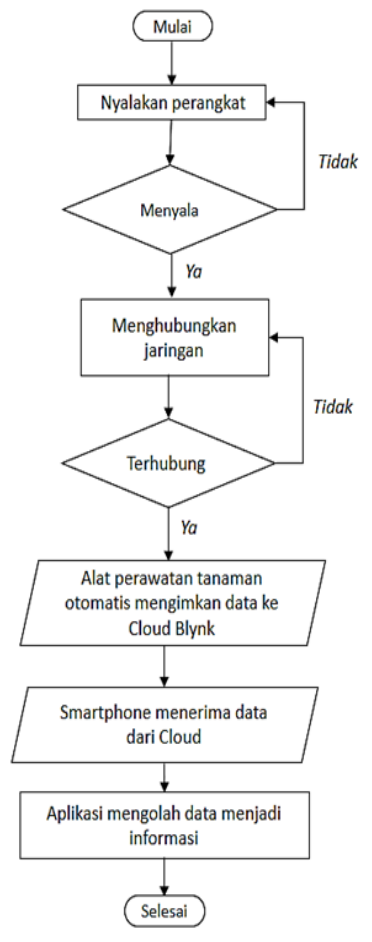

Gambar 9 Analisis Sistem pada Hardware yang diusulkan

Pada gambar 9 dimulai dengan user menyalakan alat perawatan tanaman otomatis. Setelah itu memastikan apakah jaringan internet telah tersedia di smartphone, dan memastikan kembali bahwa SSID Arduino telah sinkron dengan SSID di smartphone. Setelah itu user membuka aplikasi Sistem Perawatan Tanaman berbasis Internet of Things. Jika sudah terhubung internet, maka aplikasi akan memberikan notice bahwa aplikasi telah siap diakses. Setelah itu sensor DHT11 akan mengirimkan data terkait referensi suhu sebuah ruangan pada microcontroller ESP 8266 yang telah terintegrasi dengan cloud. Lalu smartphone menerima data dari Cloud. Kemudian aplikasi akan mengolah data menjadi informasi, apakah perlu dilakukan penyiraman atau pencahayaan atau tidak perlu melakukan tugas, karena kondisi kelembapan dan temperatur tanah sudah sesuai standar. Apabila semua berjalan dengan baik, maka selesai, user tinggal memantau kondisi tanaman hanya melaui smartphone

\subsection{Perancangan}

\section{Perancangan Hardware}

Perancangan hardware dalam penelitian ini menggunakan komponen-komponen elektro untuk membuat board IoT, blok diagram hardware dapat dilihat pada gambar dibawah ini.

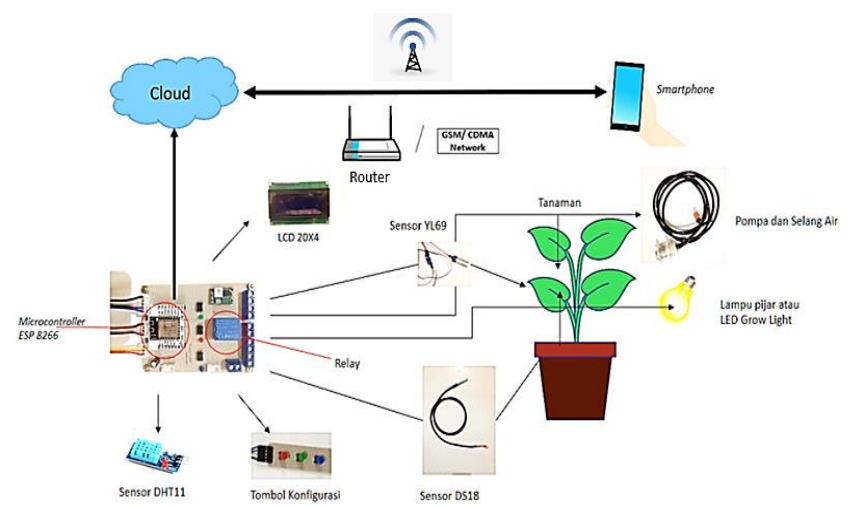

Gambar 10 Blok Diagram Hardware

Sistem ini menggunakan smartphone yang sudah terinstal aplikasi, Sistem Informasi Perawatan Tanaman dan terhubung ke internet untuk berkomunikasi dengan Microcontroller ESP8266 agar dapat dikendalikan dari jarak jauh. Perintah yang diberikan oleh aplikasi berupa relay yang terhubung dengan pompa air, lampu, kemudian aplikasi mendapatkan data suhu dan kelembaban udara yang diperoleh dari sensor DHT11, kelembapan tanah melalui sensor YL69, dan temperatur tanah dari sensor DS18. Kemudian datadata tersebut diproses oleh Microcontroller ESP 8266, sehingga menghasilkan informasi pada aplikasi di smartphone maupun di LCD. Penyiraman dan pencahayaan akan bekerja secara otomatis, karena parameter yang sudah diatur, ketika melakukan pemrograman di Arduino.

\section{Perancangan Sistem}

Perancangan sistem merupakan tahap selanjutnya setelah analisa sistem, mendapatkan gambaran dengan jelas tentang apa yang dikerjakan pada analisa sistem, maka dilanjutkan dengan memikirkan bagaimana merancang sistem informasi tersebut. Berikut pemodelan sistem dapat dilihat pada use case diagram dibawah ini. 


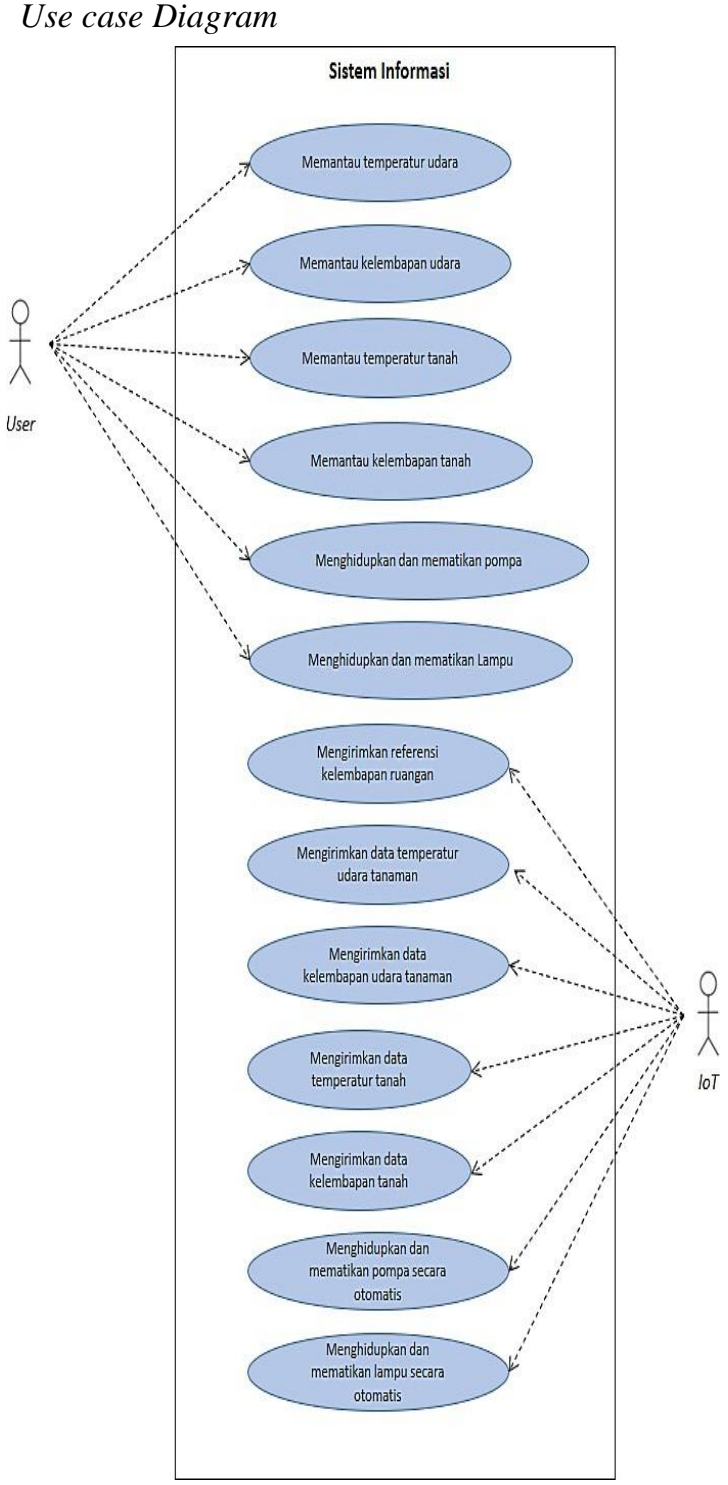

Gambar 11 Use Case Diagram

Activity Diagram nilai temperatur ruangan dapat dilihat pada gambar dibawah ini.

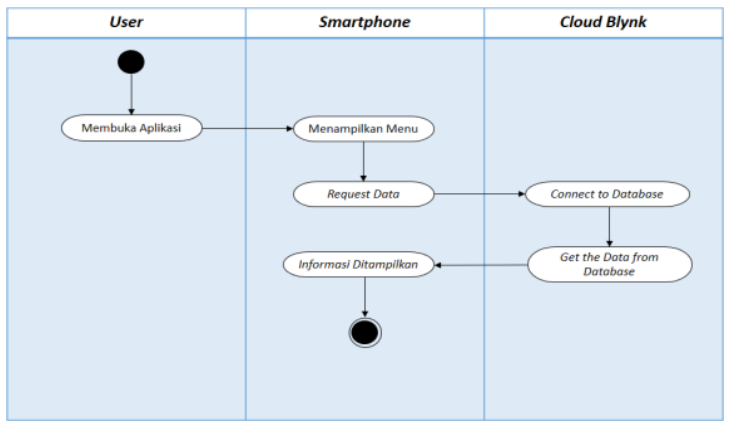

Gambar 12 Activity Diagram nilai temperatur ruangan
Sequence Diagram untuk Melihat Nilai Temperatur Ruangan dapat dilihat pada gambar dibawah ini.

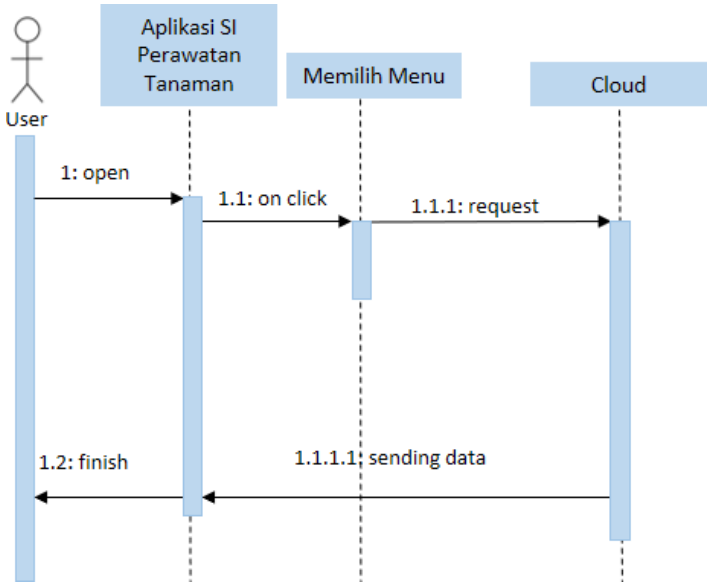

Gambar 13 Sequence Diagram Melihat Nilai Temperatur Ruangan

\section{Implementasi \& Pengujian}

\subsection{Implementasi Software}

Implementasi software merupakan tampilantampilan pada aplikasi perawatan tanaman sebagai pemberian informasi secara visual mengenaik perawatan tanaman. Implementasi antar muka dapat dilihat pada gambar berikut:

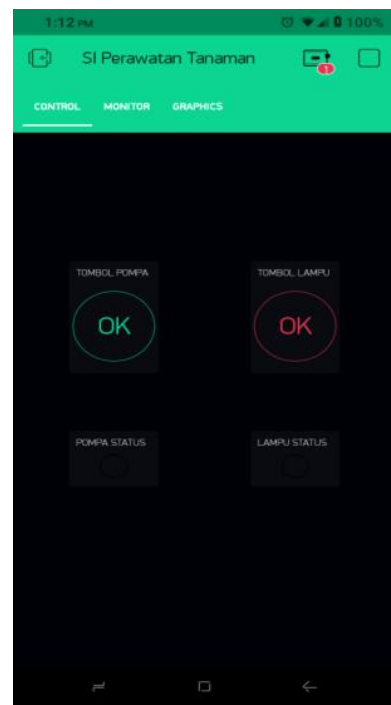

Gambar 15 Tampilan Aplikasi pada Menu Control

Gambar di atas merupakan tampilan awal dari Aplikasi Sistem Informasi Perawatan Tanaman berbasis Internet of Things, dimana terdapat Menu Control, berupa status tombol pompa, dan tombol lampu. 


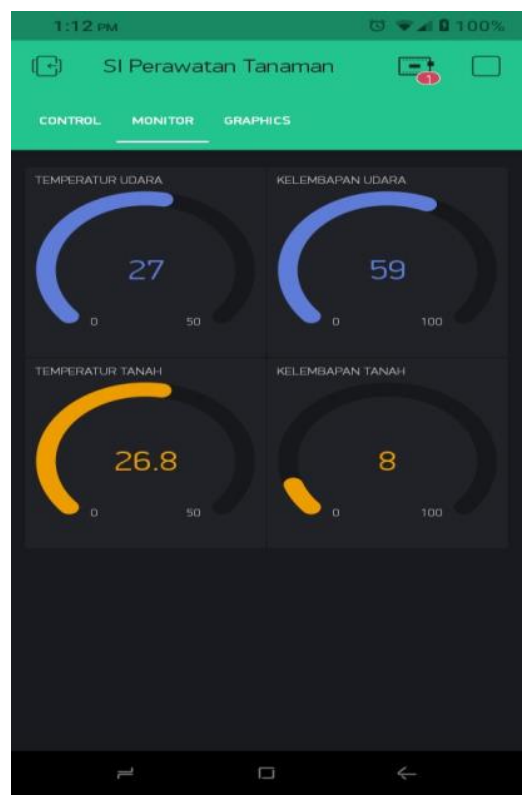

Gambar 16 Tampilan Aplikasi pada Menu Monitor

Gambar tersebut merupakan tampilan menu kedua dari aplikasi Sistem Informasi Perawatan Tanaman berbasis IoT, dimana terdapat Menu Monitor, berupa temperatur udara, kelembapan udara, temperatur tanah dan kelembapan tanah.

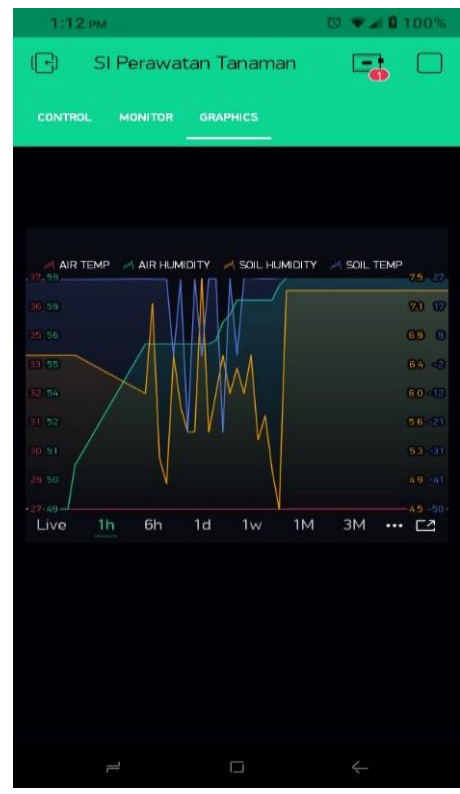

Gambar 17 Tampilan Aplikasi pada Menu Graphics

Gambar di atas merupakan tampilan menu ketiga dari Aplikasi Sistem Informasi Perawatan Tanaman berbasis IoT, dimana terdapat Menu Graphics, berupa temperatur udara, kelembapan udara, temperatur tanah dan kelembapan tanah yang dapat dipantau secara live.

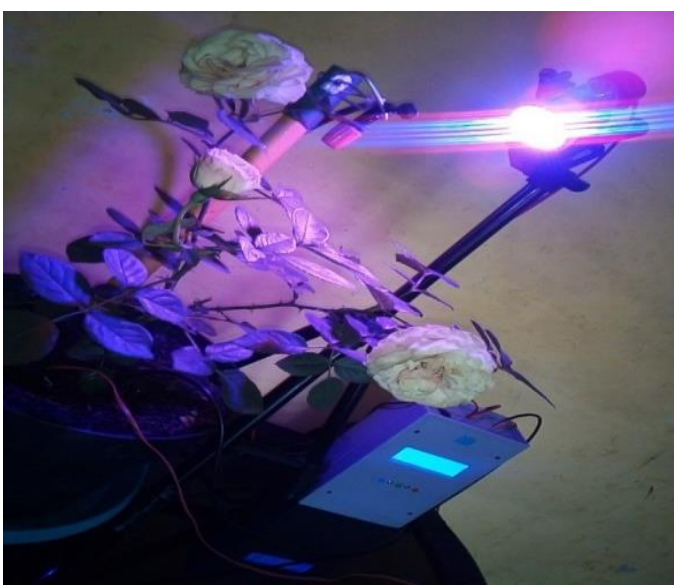

Gambar 18 Implementasi pada tanaman bunga mawar

\subsection{Pengujian}

Selanjutnya, uji coba pada LCD hardware untuk Sistem Informasi Perawatan Tanaman berbasis Internet of Things

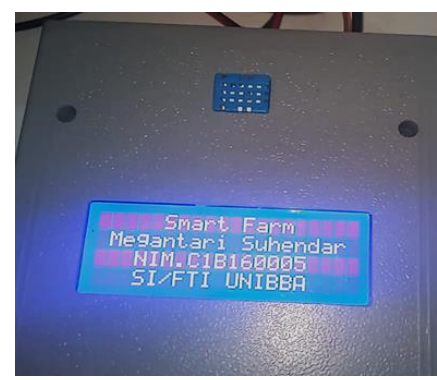

(a)

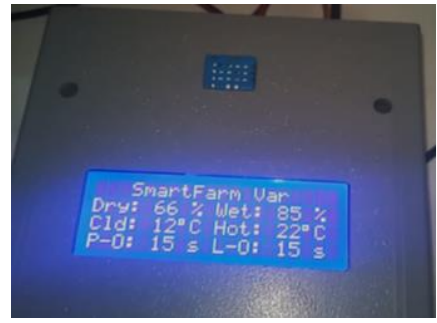

(b)

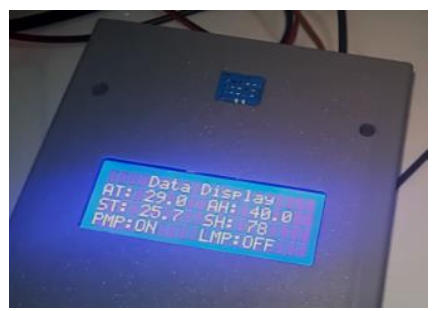

(c)

Gambar 19 Uji coba pada tampilan awal LCD (a), Uji coba saat updating sensor (b), Uji coba data display kondisi tanaman (c). 
Tabel 1 Pengujian Software pada Menu Graphic

\begin{tabular}{|c|c|c|}
\hline Deskripsi & Yang diharapkan & Hasil \\
\hline Melihat kondisi Graphics & $\begin{array}{c}\text { Menampilkan nilai temperatur dan } \\
\text { kelembapan udara serta temperatur, } \\
\text { kelembapan tanah dalam bentuk statistik }\end{array}$ & OK \\
\hline
\end{tabular}

Tabel 2 Pengujian Sensor-sensor

\begin{tabular}{|c|c|c|}
\hline Deskripsi & Yang diharapkan & Hasil \\
\hline DHT11 & Mengirimkan data kelembapan dan temperatur udara & OK \\
\hline DS18 & Mengirimkan data temperatur tanah & OK \\
\hline YL69 & Mengirimkan data kelembapan tanah & OK \\
\hline
\end{tabular}

Tabel 3 Pengujian Penyiraman Otomatis

\begin{tabular}{|c|c|c|}
\hline Deskripsi & Yang diharapkan & Hasil \\
\hline $\begin{array}{c}\text { ESP 8266 Menerima Data dari DHT11 } \\
\text { dan YL69 }\end{array}$ & Pompa mampu menarik air & OK \\
\hline
\end{tabular}

Tabel 4 Pengujian Pencahayaan Otomatis

\begin{tabular}{|c|c|c|}
\hline Deskripsi & Yang diharapkan & Hasil \\
\hline $\begin{array}{c}\text { ESP 8266 Menerima Data dari DHT11 } \\
\text { dan DS18 }\end{array}$ & Lampu Menyala & OK \\
\hline
\end{tabular}

\section{KESIMPULAN}

\subsection{Kesimpulan}

Adapun kesimpulan yang didapat dalam penelitian ini:

1. Berdasarkan hasil penelitian, penulis telah berhasil melakukan perawatan tanaman sesuai dengan tujuan penelitian, berupa penyiraman otomatis, pencahayaan otomatis, pemantauan terhadap temperatur dan kelembapan udara, serta temperatur dan kelembapan tanah pada tanaman di taman Balad Ciparay Kab. Bandung yang dapat dipantau dengan mudah melalui aplikasi di smartphone.

2. Berdasarkan data yang didapat penulis pada pemantauan temperatur udara dan kelembapan udara untuk tanaman bunga mawar di taman Balad Ciparay Kab. Bandung, temperatur udara tanaman terendah $21^{\circ} \mathrm{C}$ pada jam 07.00 WIB, 01 Juli 2020. Kemudian temperatur udara tanaman tertinggi $32^{\circ} \mathrm{C}$ pada 15 Juli 2020 jam 13.00 WIB. Nilai kelembapan udara rata-rata berada di $74 \%$ pada 19 Juli 2020.

3. Berdasarkan hasil pengujian yang dilakukan penulis menggunakan metode whitebox testing menunjukkan hasil, dari pengujian software yang dilakukan sebanyak 5 pengujian, didapatkan 5 tes berhasil atau sesuai dengan yang diharapkan, dan dari pengujian hardware yang dilakukan sebanyak 5 pengujian didapatkan 5 tes berhasil atau sesuai dengan yang diharapkan oleh responden, dan pemilik usaha Balad.

\subsection{Saran}

Adapun saran pada penelitian ini adalah:

1. Diharapkan perancangan sistem informasi kedepannya adalah pengembangan sistem informasi perawatan tanaman berbasis IoT ini dapat dipergunakan dan dikembangkan lebih luasnya lagi pada skala manufaktur.

2. Kedepannya untuk pengembangan sistem informasi yang dibangun dari segi hardware atau perangkat keras, ditambahkan actuator seperti pemberian pupuk dan pestisida.

\section{PUSTAKA}

Bachri, A., \& Utomo, E. W. (2017). Prototype Penyiram Tanaman Otomatis Dengan Sensor Kelembaban Tanah Berbasis Atmega 328. Jurnal Elektro, 2(1), 5-10. https://doi.org/10.30736/je.v2i1.33

Doshi, J., Patel, T., \& Bharti, S. K. (2019). Smart Fanning using IoT, a solution for optimally monitoring fanning conditions. Procedia Computer Science, 160, 746-751. https://doi.org/10.1016/j.procs.2019.11.016

Gondchawar, N., \& Kawitkar, R. S. (2016). IoT based smart agriculture. International Journal of Advanced Research in Computer and Communication Engineering, 5(6), 838-842. https://doi.org/10.17148/IJARCCE.2016.5618 8

Gotarane, V., \& Raskar, S. (2020). Smart Irrigation Environment.

Https://Www.Researchgate.Net/Publication/3 42466029, June.

Istiyanto, J. E. (2018). Pemograman Sensor Smartphone Android dalam Eksperimen Fisika. Andi.

Kadir, A. (2014). Pengenalan Sistem Informasi (revisi). Andi.

Suma, N., Samson, S. R., Saranya, S., Shanmugapriya, G., \& Subhashri, R. (2017). IOT Based Smart Agriculture Monitoring System. International Journal on Recent and Innovation Trends in Computing and Communication, 5(2), 177-181. 
Tarigan, J., \& Bukit, M. (2018). Rancang Bangun Sistem Penyiraman Tanaman Secara Mandiri Berbasis Mikrokontroller Atmega 8535.

Jurnal Fisika : Fisika Sains Dan Aplikasinya, 3(3), 137-141.

https://doi.org/10.35508/fisa.v3i3.615

Tulus Pranata, Beni Irawan, I. (2015). Penerapan

Logika Fuzzy Pada Sistem Penyiraman

Tanaman Otomatis Berbasis Mikrokontroler.

Jurnal Coding, Sistem Komputer Untan,

03(2), 11-22. 